\title{
Low genetic diversity in captive populations of the critically endangered Blue-crowned Laughingthrush (Garrulax courtoisi) revealed by a panel of novel microsatellites
}

\author{
Guoling Chen ${ }^{1}$, Chenqing Zheng ${ }^{2}$, Nelson Wan ${ }^{3}$, Daoqiang Liu ${ }^{4}$, Vivian Wing Kan Fu ${ }^{5}$, Xu Yang ${ }^{2}$, Yat- \\ tung Yu ${ }^{5}$, Yang Liu ${ }^{\text {Corresp. } 1}$ \\ 1 Department of Ecology, School of Life Sciences, The State Key Lab of BioControl and Sun Yet-sen University, Guangzhou, Guangdong, China \\ 2 Shenzhen Realomics Biological Technology Ltd, Shenzhen, Guangdong, China \\ 3 Ocean Park Corporation Hong Kong, Aberdeen, Hong Kong S.A.R., China \\ 4 Nanchang Zoo, Nanchang, Nanchang, Jiangxi, China \\ 5 The Hong Kong Bird Watching Society, Kowloon, Hong Kong S.A.R., China \\ Corresponding Author: Yang Liu \\ Email address: liuy353@mail.sysu.edu.cn
}

Background. Captive populations permit research and conservation of endangered species in which these efforts are hardly implemented in wild populations. Thus, analysing genetic diversity and structure of captive populations offers unique opportunities. One example is the critically endangered Bluecrowned Laughingthrush , Garrulax courtoisi, which has only two known wild populations in Wuyuan, jiangxi and Simao, Yunnan, China. We carried out the first conservation genetic study, in order to provide useful implications that allow for successful ex situ conservation and management of the Blue-crowned Laughingthrush.

Methods. Using the novel microsatellite markers developed by whole-genome sequencing, we genotyped two captive populations, from the Ocean Park Hong Kong, which are of unknown origin, and the Nanchang Zoo, which were introduced from the Wuyuan wild population since the year 2010-2011, respectively. The genetic diversity of captive Blue-crowned Laughingthrush populations was estimated based on genetic polymorphisms revealed by a new microsatellite data set and mitochondrial sequences.Then, we characterised the population structure using STRUCTURE, principal coordinates analysis, population assignment test using the microsatellite data, and haplotype analysis of mitochondrial data. Additionally, we quantified genetic relatedness based on the microsatellite data with ML-Relate.

Results. Our results showed equally low levels of genetic diversity of the two captive Blue-crowned Laughingthrush populations. The population structure analysis, population assignment test using the microsatellite data, and haplotype analysis of the mitochondrial data showed weak population structuring between these two populations. The average pairwise relatedness coefficient was not significant, and their genetic relatedness was quantified.

Discussion. This study offers a genetic tool and consequently reveals a low level of genetic diversity within populations of a critically endangered bird species. Furthermore, our results indicate that we cannot exclude the probability that the origin of the Hong Kong captive population was the wild population from Wuyuan. These results provide valuable knowledge that can help improve conservation management and planning for both captive and wild Blue-crowned Laughingthrush populations. 
1 Original paper

2

Low genetic diversity in captive populations of the critically endangered Blue-crowned Laughingthrush (Garrulax courtoisi) revealed by a panel of novel microsatellites

6 Guoling Chen ${ }^{1}$, Chenqing Zheng ${ }^{2}$, Nelson Wan ${ }^{3}$, Daoqiang Liư ${ }^{4}$, Vivian Wing Kan, Fu ${ }^{5}$, Xu Yang ${ }^{2}$,

7 Yat-tung $\mathrm{Yu}^{5}$, Yang Liu ${ }^{1 *}$

8

$9{ }^{1}$ State Key Laboratory of Biocontrol, Department of Ecology and School of Life Sciences, Sun

10 Yat-sen University, Guangzhou, 510275, China

112 Shenzhen Realomics Biological Technology Ltd, Shenzhen, 518000, P. R. China

$12{ }^{3}$ Ocean Park Corporation Hong Kong, Aberdeen Hong Kong S.A.R., China

$13{ }^{4}$ Nanchang Zoo, Nanchang, 330025, China

145 The Hong Kong Bird Watching Society, Kowloon Hong Kong S.A.R., China

15

16

17

*Correspondence: Dr. Yang Liu, Email: liuy353@mail.sysu.edu.cn; Fax: +86 2084110436 


\section{Abstract}

28 Background. Captive populations permit research and conservation of endangered species in which these efforts are hardly implemented in wild populations. Thus, analysing genetic diversity and structure of captive populations offers unique opportunities. One example is the critically endangered Blue-crowned Laughingthrush, Garrulax courtoisi, which has only two known wild populations in Wuyuan, Jiangxi and Simao, Yunnan, China. We carried out the first conservation genetic study, in order to provide useful implications that allow for successful ex situ conservation and management of the Blue-crowned Laughingthrush.

Methods. Using the novel microsatellite markers developed by whole-genome sequencing, we genotyped two captive populations, from the Ocean Park Hong Kong, which are of unknown origin, and the Nanchang Zoo, which were introduced from the Wuyuan wild population since the year 2010-2011, respectively. The genetic diversity of captive Blue-crowned Laughingthrush populations was estimated based on genetic polymorphisms revealed by a new microsatellite dataset and mitochondrial sequences. Then, we characterised the population structure using STRUCTURE, principal coordinates analysis, population assignment test using the microsatellite data, and haplotype analysis of mitochondrial data. Additionally, we quantified genetic relatedness based on the microsatellite data with ML-Relate.

Results. Our results showed equally low levels of genetic diversity of the two captive Bluecrowned Laughingthrush populations. The population structure analysis, population assignment test using the microsatellite data, and haplotype analysis of the mitochondrial data showed weak population structuring between these two populations. The average pairwise relatedness coefficient was not significant, and their genetic relatedness was quantified.

Discussion. This study offers a genetic tool and consequently reveals a low level of genetic diversity within populations of a critically endangered bird species. Furthermore, our results indicate that we cannot exclude the probability that the origin of the Hong Kong captive population was the wild population from Wuyuan. These results provide valuable knowledge that 
53 can help improve conservation management and planning for both captive and wild Bluecrowned Laughingthrush populations.

Introduction

Many endangered species require captive breeding to save them from extinction, as they are incapable of surviving in inhospitable natural environments because of direct or indirect human impacts in the form of habitat loss, overexploitation, pollution, or introduced predators, competitors, or diseases (Frankham, 2008; Frankham et al., 2010). For conservation management of captive populations, it is necessary to understand some baseline genetic information, such as the genetic diversity and population structure, to maintain the genetic "health" of species for long-term viability (Frankham et al., 2010). Furthermore, captive populations provide ideal systems for ecological, evolutionary, and genetic research of endangered species, because it is easier and safer to obtain DNA samples and observe the ecological habit of endangered species (Ballou \& Foose, 1996; Frankham, 2010; Frankham et al., 2010). Therefore, it is both extremely important and efficient to use captive populations as a resource to elucidate the genetic status of endangered species, and to plan appropriate genetic management (Frankham, 2008;

69 Frankham et al., 2010).

Because of their relatively high level of polymorphism, repeatability in genotyping and high PCR amplification success, microsatellites are advantageous genetic tool to address conservation and behavioural genetic patterns in threatened species towards their conservation and management issues (Faria et al., 2016; Wang et al., 2017). A key part of microsatellite-based conservation genetics is to develop either species-specific or cross-species primer sets, with the development of next-generation sequencing, the development of reliable microsatellites are no longer an timeconsuming task, even for birds that have few known microsatellite loci in their genomes (Castoe et al., 2012; Wang et al., 2017; Yang et al., 2017). 
80 The Blue-crowned Laughingthrush, Garrulax courtoisi, is listed as "Critically Endangered" by the 81 IUCN Red Data Book (Birdlife International, 2017) and has an extremely restricted distribution in 82 south-eastern China. The entire known wild population of the nominate subspecies, which 83 consists of approximately 300 individuals, is restricted to six fragmented sites in Wuyuan County, 84 Jiangxi Province, China (He et al., 2017). Historical records indicate a disjunct population of the 85 in southern Yunnan Province, sometimes treated as a distinct subspecies G. c. simaoensis (Cheng 86 \& Tang, 1982; He et al., 2017). However, the current status of this population is not known, and 87 it has not been encountered in the wild since 1956 (Wilkinson \& He, 2010a). In addition, around 88200 captive Blue-crowned Laughingthrush individuals are kept in several zoos in China, Europe, and America without known subspecies origin (Wilkinson \& Gardner, 2011; Wilkinson et al., 90 2004).

Most recent studies on this rare species focused on habitat use and ecology in the wild Wuyuan population (He et al., 2017; Wilkinson \& He, 2010a; Zhang et al., 2017), breeding ecology of captive populations (Liu et al., 2017; Liu et al., 2016; Wilkinson et al., 2004), and its taxonomic status and conservation management (Cheng \& Tang, 1982; Collar et al., 2016; Wilkinson \& He, 2010b; Wilkinson \& He, 2010c). However, there is no information on the genetic diversity, population structure, or other important issues pertaining to conservation genetics in either the wild or captive Blue-crowned Laughingthrush populations. Elucidating genetic diversity is thus important for producing a better understanding of microevolutionary processes and developing appropriate conservation and management strategies of Blue-crowned Laughingthrush.

102 Here, we present the first conservation genetic analysis of Blue-crowned Laughingthrush using mitochondrial DNA and a novel set of microsatellite markers developed by next-generation sequencing using the Illumina high-throughput sequencing platform. We characterised the 
105 genetic diversity, genetic structure, and relatedness in the only two captive populations in China,

106 namely, the Ocean Park Hong Kong and the Nanchang Zoo. Specifically, we attempted to learn

107 two aspects. First, whether the two captive populations have a low level of genetic diversity and

108 a sign of inbreeding, as expected for an endangered species. Second, whether the introduced

109 origin of the population in the Ocean Park Hong Kong was from Wuyuan wild population, using

110 the population of the Nanchang Zoo as a reference.

111

\section{Materials and Methods}

\section{Sample collection and DNA extraction}

114 The Ocean Park Hong Kong (OPHK) population was introduced in 1989, and the existing

115 population size is 16 individuals. Both the source and individual relationships of Blue-crowned

116 Laughingthrush are unknown because of foot ring loss and lack of records. The Nanchang Zoo

117 (NCZ) population in Jiangxi was introduced in 2010 and 2011 from the wild Blue-crowned

118 Laughingthrush population in Wuyuan County, Jiangxi Province, and is the only captive

119 population that has a confirmed source in the world. In this population, six individuals are from

120 the wild population and the other seven individuals are their descendants.

121

122 Since this study involved sampling of endangered species, all the animal operations were

123 approved by the Institutional Ethical Committee of Animal Experimentation of Sun Yat-sen

124 University and strictly complied with the ethical conditions by the Chinese Animal Welfare Act

125 (20090606). And all sampling procedures were performed with assistance of veterinarians or zoo

126 keepers.

127

128 We collected Blue-crowned Laughingthrush samples from 23 individuals of two captive 129 populations: 14 individuals from the long-established OPHK population and nine individuals from

130 the recently established NCZ population (Table 1). Fresh blood samples from the 14 OPHK 
131 individuals were obtained in a non-invasive manner during regular veterinary examinations, and

132 muscle samples from dead individuals and three egg remains were obtained from the NCZ

133 population. All samples were stored in $95 \%$ ethanol at $-80^{\circ} \mathrm{C}$. We extracted total genomic DNA

134 using the QIAamp DNA Mini Kit (Qiagen, GmbH, Hilden, Germany) following the manufacturer's

135 protocol, and quantified DNA quality with a NanoDrop ND-1000 (Thermo Fisher Scientific,

136 Waltham, MA, USA).

137

138 Genome sequencing, microsatellite loci identification, and primer design

139 We sequenced the whole genome from one sample of Blue-crowned Laughingthrush (No.

140 SYSb6040) from OPHK, and then used it as the draft genome. P5 and P7 adapters were ligated to

141 the fragments after the genomic DNA was digested. The P5 adapter contains a forward

142 amplification primer site, an Illumina sequencing primer site, and a barcode. The selected

143 fragments were end-repaired and $3^{\prime}$ adenylated, and these fragments were PCR amplified with

144 P5- and P7-specific primers. Our library was validated using the Agilent Technologies 2100 Bio-

145 analyzer and ABI StepOnePlus Real-Time PCR System. After adapter ligation and DNA cluster

146 preparation, the samples were sequenced using a Hiseq X-ten sequencer (BGI, Shenzhen, China).

148 Raw data from this single individual were processed by removing adapter sequences and

149 subsequently removing the reads. Sequences with a low-quality rate [quality value $\leq 5$ (E)] greater

150 than or equal to $50 \%$ and with more than $10 \%$ unknown (' $N$ ') bases were removed. The final read

151 length was trimmed to 82 nucleotides (minimum length). Then, the high-quality sequences were

152 selected to assemble the reference scaffolds. The genome was assembled using a short-read

153 assembly method in SOAPdenovo2 (Li et al., 2010). A de Bruijn graph was built by splitting the

154 reads into K-mers from the short-insert libraries (270 bp) without using pairing information. After

155 a series of graph simplifications, the reads were assembled into contigs. All available paired-end

156 reads were realigned onto the contig sequences to infer linkage between contigs. The linkage 
157 was removed if it was supported by unreliable paired-end reads. To simplify the contig linkage 158 graph, we used subgraph linearisation, which extracted information on unambiguously linear 159 paths. Iterative scaffolding was carried out to estimate insert size. Finally, to fill the intra-scaffold 160 gaps, a local assembly was performed to locate the reads in the gap region, thus ensuring the 161 other end of a scaffold was uniquely mapped to the linked contig.

162

163 We identified the microsatellites by screening the sequence data for di-, tri-, tetra-, and penta164 nucleotide motifs with a minimum of six, five, five, and five repeats, respectively, by using the 165 polymorphism information from the Blue-crowned Laughingthrush draft genome. Then we 166 designed the primers in MSATCOMMANDER v.1.0.8 (Faircloth, 2008) and Primer 3 (Rozen \&

167 Skaletsky, 2000) to minimize potential structural or functional defects. After these procedures, 168 we randomly selected a panel of 20 novel di-nucleotide markers and 10 tri-nucleotide markers.

\section{Microsatellite genotyping}

171 The 30 selected loci were arranged into eight PCR multiplex sets (2-4 loci per set); each forward 172 primer was labelled with fluorescent dye on the $5^{\prime}$ end of the forward primers, and the sequence 173 GTTTCTT was placed on the $5^{\prime}$ end of the reverse primer (Brownstein et al., 1996). PCR amplifications were performed in a reaction volume of $10 \mu \mathrm{L}$, containing, $5 \mu \mathrm{L} 2 \times \mathrm{PCR}$ mix

175 (QIAGEN Multiplex Kit), $2 \mu \mathrm{L} 5 \times$ Q-Solution, $1 \mu \mathrm{L}$ of a primer mix and $1 \mu \mathrm{L}$ of template DNA. The 176 cycling conditions were as follows: initial denaturation at $95^{\circ} \mathrm{C}$ for $15 \mathrm{~min}$, followed by 35 cycles 177 of denaturation at $94{ }^{\circ} \mathrm{C}$ for $30 \mathrm{~s}$, annealing at $58{ }^{\circ} \mathrm{C}$ for $90 \mathrm{~s}$ and at $72{ }^{\circ} \mathrm{C}$ for $90 \mathrm{~s}$, and a final 178 extension at $72{ }^{\circ} \mathrm{C}$ for 10 min. Products were isolated and detected on an $\mathrm{ABI}$ Prism $3730 \mathrm{XL}$

179 Genetic Analyzer (Applied Biosystems, Carlsbad, CA, USA), and the fragment lengths were 180 determined against an internal size standard (GeneScan ${ }^{\mathrm{TM}} 500$ LIZ Size Standard, Applied 181 Biosystems, Carlsbad, CA, USA) with GeneMapper v.3.7 (Applied Biosystems, Carlsbad, CA, USA). 182 All samples were genotyped at the 30 microsatellite loci that were developed from the Blue- 
183 crowned Laughingthrush draft genome. We ultimately selected 19 microsatellite loci for our 184 study and discarded the remaining ones because of low polymorphism.

185

186

\section{Mitochondrial DNA sequencing}

187 To infer maternal relatedness of sampled individuals, partial mitochondrial cytochrome b (cytb) sequences were amplified and sequenced using the primers L14995 and H16065 (Groth, 1998). PCR amplifications were performed in a $20-\mu \mathrm{L}$ reaction volume that contained $1-2 \mu \mathrm{L}$ template DNA (50-100 ng), $10 \mu \mathrm{L} 2 \times$ buffer, $2 \mu \mathrm{L}$ dNTPs $(2 \mathrm{mM}), 0.5 \mu \mathrm{L} \mathrm{MgCl}_{2}(2.5 \mathrm{mM}), 0.5 \mu \mathrm{L}$ of each

191 primer (10 mM), and $0.5 \mu \mathrm{L}$ (1 unit/ $\mu \mathrm{L})$ KOD DNA polymerase (Toyobo, Osaka, Japan). The PCR

192 cycling conditions were as follows: an initial denaturation step of 4 min at $94{ }^{\circ} \mathrm{C}$ followed by 35 193 cycles of $40 \mathrm{~s}$ denaturation at $94{ }^{\circ} \mathrm{C}, 40 \mathrm{~s}$ annealing at $56^{\circ} \mathrm{C}$, and 90 s extension at $72{ }^{\circ} \mathrm{C}$, followed

194 by a final 10 min extension at $72{ }^{\circ} \mathrm{C}$. The purified products were sequenced with both forward and reverse primers using a BigDye Terminator v.3.1 Cycle Sequencing Kit (Applied Biosystems, Carlsbad, CA, USA) according to the manufacturer's guidelines. The products were sequenced on an ABI Prism 3730 Automated DNA sequencer (Shanghai Majorbio Bio-pharm Technology Co., Ltd., Shanghai, China). Additional PCR profile information is provided as supplementary information (Supplementary Material Appendix 1, Table S2).

200

\section{Genetic diversity estimates}

202 For each microsatellite locus, we calculated the frequency of null alleles using Cervus v.3.0.7 203 (Kalinowski et al., 2007); then, we used Arlequin v.3.5 (Excoffier \& Lischer, 2010) to further test

204 for Hardy-Weinberg equilibrium using 1000 permutations and pairwise linkage disequilibrium by 205 performing 100,000 Markov chain steps. Based on these three tests, seven out of 19 loci were removed from the dataset. To obtain genetic diversity estimates, we calculated the number of different alleles $\left(\mathrm{N}_{\mathrm{a}}\right)$, average allelic richness $\left(A_{R}\right)$, observed heterozygosity $\left(\mathrm{H}_{\mathrm{O}}\right)$, and expected heterozygosity $\left(H_{E}\right)$ using the remaining 12 loci in GenAlEx v.6.5.1 (Peakall \& Smouse, 2012). We 
209 also calculated the inbreeding index $\left(F_{\mid S}\right)$ for each population and assessed the significance of this

210 index based on 10,000 permutations in Arlequin v.3.5.

211

212 In addition, we carried out rarefication analysis using POWSIM v.4.0 (Ryman \& Palm, 2006) to

213 assess the statistical power of our microsatellite markers to detect levels of population

214 differentiation and relatedness (e.g. Liu et al., 2011). Using an estimated effective size $\left(\mathrm{N}_{\mathrm{e}}\right)$ of

2151000 for the base population, we performed 1000 runs and generated eight predefined levels of

216 population differentiation $\left(F_{S T}=0.001,0.0025,0.005,0.01,0.02,0.025,0.05,0.075\right)$, with sample

217 sizes, numbers of markers, and allele frequencies corresponding to the empirical data. The

218 proportion of significant outcomes $(P<0.05)$ then corresponded to an estimate of power. The

$219 \mathrm{H}_{\mathrm{O}}$ at each locus was tested for equal allele frequencies by both Pearson's traditional contingency

220 chi-square and Fisher's exact tests. The information from all loci was then combined by summing

221 the data from chi-square and Fisher's methods (Ryman \& Jorde, 2001; Ryman \& Palm, 2006).

222

223 Genetic population structure

224 For the microsatellite dataset, we applied four methods to estimate genetic population structure.

225 First, we calculated pairwise $\mathrm{F}_{\mathrm{ST}}$ between these two populations, and derived significance levels using 10,000 permutations in Arlequin v.3.5. Sequential Bonferroni correction (Rice, 1989) was used to adjust the significance levels for multiple testing. Second, we further tested the genetic structure using the Bayesian clustering method in STRUCTURE v2.3 (Falush et al., 2003; Pritchard et al., 2000). Using the Bayesian admixture model with the correlated allele frequencies option, we performed 1,000,000 Markov chain Monte Carlo (MCMC) iterations, with the first 200,000

231 discarded as burn-in. We conducted 10 independent runs for each K-value, the possible number

232 of genetic cluster $(K=1-4)$ for the entire dataset. We then used Structure Harvester v.0.6.8 (Earl

233 \& Vonholdt, 2012) to identify the most likely number of genetic clusters based on the ad hoc 234 statistics described in Evanno et al. (2005), in which both L(K), the posterior probability, $\operatorname{Ln} P(D)$ 
235 increased per $K$, and $\Delta K$ means the second order rate of change of the $L n P(D)$ with respect to

236 the number of clusters were estimated and compared. The final results for individual

237 memberships were visualised by bar plot in DISTRUCT v.1.1 (Rosenberg, 2004). Third, principal

238 coordinates analysis (PCOA) with pairwise Euclidian distances was carried out in GenAlEx v.6.5.1

239 (Peakall \& Smouse, 2012) to visualise genetic relationships among individuals. Last, the biplots of

240 pairwise population assignment likelihood values was computed using gamete-based Monte

241 Carlo resampling method with a threshold of 0.01 in GenAlEx v.6.5.1 (Paetkau et al., 2004; Peakall

$242 \&$ Smouse, 2012). This method uses genotype likelihoods to assign the possible population origins

243 of individuals and allows estimation of dispersal events (Paetkau et al., 2004).

245 For DNA sequence data, we aligned the mitochondrial sequences using the Clustal W algorithm

246 (Thompson et al., 1994) in MEGA v.6.06 (Tamura et al., 2013) with default parameters. The

247 alignment was checked and manually adjusted when needed. To estimate the level of genetic

248 polymorphism, basic genetic polymorphism statistics, such as haplotype number (h), haplotype

249 diversity $(\mathrm{Hd})$, number of segregating sites $(\mathrm{S})$, and nucleotide diversity $(\pi)$, of each population

250 were calculated in DnaSP v.5.10.1 (Librado \& Rozas, 2009). Then, this gene was analysed by

251 haplotype network analysis using the reduced median-joining method (Bandelt et al., 1999) in

252 PopART v.4.8.4 (Leigh \& Bryant, 2015).

253

254 Relatedness analysis

255 For all relatedness estimates, the individuals from the OPHK and NCZ populations were 256 separately analysed. For each pair of individuals from the OPHK or NCZ population, we calculated 257 the Queller and Goodnight (1989) estimator of relatedness (RG) using GenAlEx v.6.5.1 (Peakall 258 \& Smouse, 2012). The genetic relatedness coefficient is defined as the proportion of ancestral 259 alleles that are shared between descendants (Lynch \& Walsh, 1998). 
261 Then, the maximum likelihood estimates of relatedness ( $R$ ) was calculated in ML-Relate

262 (Kalinowski et al., 2006), and the likelihood of four relatedness categories [unrelated: $\mathrm{R}$ = 0; close

263 kin (e.g. half-siblings, aunt-niece): $R=0.25$; full-siblings: $R=0.5$; parent-offspring: $R=0.5]$ was

264 used to determine the proportion of a specific relatedness category. To assess the likelihood of

265 a given relatedness category relative to the other three categories, a likelihood ratio test using a $26695 \%$ confidence level and 1000 simulations was carried out in ML-Relate (Kalinowski et al., 2006).

267

268 Results

269 Genome sequencing, microsatellite loci identification, and primer design

270 The whole genome of the endangered Blue-crowned Laughingthrush was first assembled using

271 the high-coverage (approximately 40x) sequence reads. After processing of the approximately

$27241.18 \mathrm{~Gb}$ of raw data and removal of ambiguous barcodes, about $39.1 \mathrm{~Gb}$ of clean data were 273 retained. The assembly generated 1089819 scaffolds larger than 100 bp, with an N50 contig size 274 of $1297 \mathrm{bp}$ and an N50 scaffold size of $4548 \mathrm{bp}$. The microsatellite detection generated 70310 275 markers with 31216 di-nucleotide repeats, 21195 tri-nucleotide repeats, 10892 tetra-nucleotide 276 repeats, and 7007 penta-nucleotide repeats.

277

\section{Genetic diversity}

279 For the microsatellite dataset, we obtained the 12 loci from 14 individuals from the OPHK 280 population and nine individuals from the NCZ population (Table 1). We found no evidence of 281 genotypic disequilibrium after Bonferroni correction. The number of alleles per locus ranged 282 from two to five, and the polymorphic information content per locus ranged between 0.16 and 283 0.70. For all microsatellite loci, $\mathrm{Na}$ for each population was approximately 3.25, and $\mathrm{Na}$ of the 284 NCZ population was slightly higher than that of the OPHK population. We found low to moderate 285 genetic diversity with a mean $\mathrm{H}_{\mathrm{O}}$ of $0.36-0.45$ and a mean $\mathrm{H}_{\mathrm{E}}$ of $0.34-0.44$. Moreover, we found 
286 no sign of inbreeding at the loci, with $F_{I S}$ ranging from $-0.283(p=0.923)$ to $-0.214(p=0.784)$

287 (Table 2).

288

289

Genetic population structure

290 The simulations performed in POWSIM using our particular microsatellite data and selected

291 sample size showed that the statistical power was sufficient (> 90\%) to detect genetic

292 substructure if the true $\mathrm{F}_{\mathrm{ST}} \geq 0.075$ (Figure $\mathrm{S} 1$ ).

293

294 Using multiple approaches, we found no evidence of genetic differentiation between OPHK and

295 NCZ populations. First, significant but low genetic differentiation in the microsatellite dataset was

296 revealed by $F_{S T}$ value $(0.065, p=0.003)$ (Table 1$)$. This is because 10 out of 12 loci had non-

297 significant and low $\mathrm{F}_{\mathrm{ST}}$ values (range, -0.032-0.137), with only two exceptions (BCLT_L5: $\mathrm{F}_{\mathrm{ST}}=$ 298 0.154, $p=0.007 ;$ BCLT_L6: $\mathrm{F}_{\mathrm{ST}}=0.143, \mathrm{p}=0.006$ ) (Table 3). For the STRUCTURE analysis of 299 microsatellite data, we did not find a strong support of a particular number of genetic cluster.

300 The $\Delta \mathrm{K}$ estimator (Figure $1 \mathrm{c}$ ) suggested that there are most likely two genetic clusters. This is 301 however at odds with the mean posterior probabilities, which has its peak at $\mathrm{K}=1$ (Figure 1b).

302 Since the $\Delta K$ estimator cannot detect the situation of $K=1$ and it is also meaningless to plot

303 individual assignment of population panmixia, we further did STRUCTURE plot when K=2 (Figure

304 1a). It clearly suggests no large genetic difference between the OPHK population and NCZ

305 population. For the PCoA plot based on the 12 microsatellite sites of these two populations, we

306 found no differentiation between the OPHK and NCZ populations in the first principal coordinate

307 but little differentiation in the second principal coordinate (Figure 2a). Assignment test results

308 showed that, for the OPHK population, $100 \%$ of the individuals ( $n=14$ ) were assigned to the

309 OPHK population. For the NCZ population, $77.8 \%$ of the individuals $(n=7)$ were assigned to the

310 NCZ population, whereas 22.2\% of the individuals ( $n=2$, individuals 6041 and 6043) were

311 assigned to the OPHK population (Figure $2 \mathrm{~b}$ ). 
313 For the mitochondrial cytb dataset, we obtained 1027 bp from each individual (GenBank

314 Accession No. MH423582-MH423604). The average level of genetic diversity was similar

315 between OPHK and NCZ populations (Table 2). Haplotype networks showed that there were five

316 haplotypes among these individuals, and the most frequent haplotype was shared by 18

317 individuals. Three and one private haplotypes were owned by OPHK and NCZ populations,

318 respectively (Figure 3 ).

319

320 Relatedness analysis

321 The average pairwise relatedness coefficient based on the 12 microsatellite loci within

322 populations ranged from -0.013 to -0.05 , and none of these values significantly differed from

323 zero (Table 2). Such a low level of relatedness probably results from the fact that a small

324 proportion of individuals from both populations are closely related (Figure 4). A dominant

325 proportion of dyads came from unrelated individuals ( $72.53 \%$ in the OPHK population, $86.11 \%$ in

326 the NCZ population).

327

328 Discussion

329 We provided a set of polymorphic genetic markers for the Blue-crowned Laughingthrush from

330 scanning its genome, which is intended to be a useful genetic tool for efficient conservation of

331 this species. Consequently, we were able to estimate the genetic diversity, population structure,

332 and genetic relatedness of wild and captive populations of this endangered bird species. The

333 obvious next step is to expand the usage of this marker set for other populations in different

334 European and North American zoos (Wilkinson \& Gardner, 2011; Wilkinson et al., 2004). The

335 Global Species Management Plan for the Blue-crowned Laughingthrush has already been

336 approved and facilitates management of zoo populations (Gardner, 2013; WAZA, 2017). But

337 conservation genetic information of these populations are not clear. Absence of such information 
338 can hinder management and understanding of other genetic problems, such as inbreeding

339 depression (Frankham et al., 2010). Besides, it is also necessary to carry out long-term genetic

340 monitoring for in Wuyuan which are facing different conservation challenges (Zhang et al., 2017).

341 Furthermore, these markers could be broadly applied to conservation genetic studies of Garrulax

342 laughingthrushes, a group with great conservation concerns on illegal trade and captive breeding

343 (Collar \& van Balen, 2013; Li, 2009; Wu et al., 2012). It is noteworthy that the utility of crossing

344 species amplification of microsatellites is admittedly feasible (Dawson et al., 2010; Gu et al., 345 2012).

346

347 The present study reveals first information of genetic diversity, population structure and

348 relatedness of Blue-crowned Laughingthrush. We documented low genetic diversity in two

349 captive populations. Our results showed that genetic diversity of the OPHK population was

350 slightly lower than that of the NCZ population, but there was no significant difference between

351 them. Unexpectedly, we found no evidence of inbreeding among closely related individuals in

352 both captive populations. For the OPHK population, the best explanation is that this captive

353 population likely originated from different wild sources (as described in the section below), and

354 this might provide genetic rescue that prevented loss of genetic diversity. The results of the NCZ

355 population may be related to the short amount of time ( $<10$ years) that this population has been

356 captive. And our result of relatedness estimator may also support these results, most value of

357 the pairwise relatedness $\left(\mathrm{R}_{\mathrm{QG}}\right)$ are negative in both OPHK population and NCZ population (Table

358 S2). The more negative value means the more confident of unrelated of that two individuals, and

359 it further indicate the detection of recent immigrants that carry novel alleles (Konovalov \& Heg,

360 2008; Queller \& Goodnight, 1989). Another factor that must be considered is the statistical power

361 of the microsatellite data. Our simulation showed the power of this marker set was high (>90\%)

362 if the true $F_{S T} \geq 0.075$. However, the actual average pairwise $F_{S T}$ was 0.065 . Such weak population 
363 differentiation may cause the underestimation of the inbreeding and relatedness (Liu et al., 2011;

364 Liu et al., 2013).

365

366 We found weak signal of genetic differentiation between OPHK and NCZ populations based on

367 different methods. Although it may be some arguments about the chosen of the number of

368 clusters in STRUCTURE, since the $\Delta \mathrm{K}$ helps in identifying the correct number of clusters in most

369 situations, it cannot find the best $\mathrm{K}$ with the situation a panmictic population (Evanno et al.,

370 2005). The lack of strong population subdivision may be the most consensus result because of

371 the highest mean posterior probabilities at $\mathrm{K}=1$ (Figure $1 \mathrm{~b}$ ). Indeed, this result is consistent with

372 other methods, such as PCA, i.e. largely overlapped in PCo1 (Figure 2a), and assignment tests.

373 We inferred that these two populations only have slightly different genetic components. For

374 instance, assignment analysis revealed that two individuals of the NCZ population were inferred

375 to be from the OPHK population; this result, which may be due to the low sample size of the NCZ

376 population, further implies that higher genetic variation is present among individuals in the OPHK

377 population. Moreover, mitochondrial DNA data analysis also supported this result that most

378 individuals shared the same haplotype. However, both the OPHK and NCZ populations had

379 private haplotypes. One parsimony explanation is that at least some individuals of the OPHK

380 shared the most recently ancestor with the NCZ population, in other words, from Wuyuan wild

381 origin.

382

383 However, the population genetic analysis performed in this study, i.e. HWE tests and F-statistics,

384 (e.g. inbreeding coefficient and fixation index $\mathrm{F}_{\mathrm{ST}}$ ) were measured based on a very small sample

385 size for each captive population (14 and 7 individuals, respectively) and genotyped at 12 loci.

386 Because both HWE tests and F-statistics lie the assumption of an infinite population size (Guo \&

387 Thompson, 1992; Weir \& Cockerham, 1984), our dataset using rather small population size $(<20)$

388 may lead to ascertainment bias and an overestimation of F-statistics (Kalinowski, 2005; Willing 
389 et al., 2012). Thus the biological interpretation of these results should be used with great caution.

390 The relative precise estimates can be obtained by incorporating more individuals (Kalinowski, 391 2005) and/or more genetic markers (Willing et al., 2012). If increasing sample size is not possible,

392 usually the case for extremely rare and endangered species, it is more feasible to genotype a 393 small number of individuals at a larger number of genome-wide markers developed with high394 throughput sequencing (Davey et al., 2011; Luikart et al., 2003).

395

396 Together, our results do not support previous hypothesis that captive OPHK individuals may 397 belong to the subspecies simaoensis (Wilkinson \& Gardner, 2011; Wilkinson et al., 2004). But we 398 are unable to exclude a single source of individuals in the OPHK population. Consequently, the 399 safe conclusion is that individuals from Wuyuan, perhaps also Simao populations have 400 contributed to the OPHK population. Our results further calls the re-evaluation of the subspecies 401 status of simaoensis. Some taxonomic treatment argued that simaoensis may not be a valid 402 subspecies, as its diagnostic character, i.e. yellowish-grey breast-band sometimes also presents 403 in Wuyuan wild population (Collar et al., 2019). Because the population status of G. c. simaoensis 404 is unclear and it may have already been regionally extirpated (Wilkinson \& He, 2010a), genomic 405 approaches applied on genotyping a handful number of museum specimens of putative $G$. $c$. 406 simaoensis has great potential to resolve this issue.

407

408 Conclusions

409 Together, with the new set of markers we proposed, we estimated genetic diversity, structure 410 and relatedness of captive Blue-crowned Laughingthrush populations for the first time. 411 Information and permanent genetic resources obtained from this study can benefit effective ex 412 situ and in situ conservation efforts to recover bird species from the brink of extinction.

413

\section{Acknowledgements}


415 We are grateful to Dr. Emilio Pagani-Núñez for his comments on a previous version of this 416 manuscript. This research was supported by a grant from the Ocean Park Conservation 417 Foundation, Hong Kong, China (No. BD03_1617) to Yang Liu. We thank Mallory Eckstut, PhD, from 418 Liwen Bianji, Edanz Editing China (www.liwenbianji.cn/ac), for editing the English text of a draft of this manuscript. Two anonymous reviewers and Prof. Michael Wink provided useful comments on revising the paper.

421

422

423

424

425

426

427

428

429

430

431

432

433

434

435

436

437

438

439

440

441

442

443

444

445

446

447

448

449

450

\section{References}

BirdLife International. 2017. Species factsheet: Garrulax courtoisi. Downloaded from http://www.birdlife.org on 31/12/2017

Ballou JD, and Foose TJ. 1996. In: Kleiman DG, Lumpkin S, Allen M, Harris H, and Thompson K, eds. Demographic and genetic management of captive populations In: Wild Mammals in Captivity. University of Chicago Press, Chicago.

Bandelt HJ, Forster P, and Rohl A. 1999. Median-joining networks for inferring intraspecific phylogenies. Molecular Biology and Evolution 16:37-48.

Brownstein MJ, Carpten JD, and Smith JR. 1996. Modulation of non-templated nucleotide addition by Taq DNA polymerase: primer modifications that facilitate genotyping. BioTechniques 20:1004-1006, 1008-1010.

Castoe TA, Poole AW, de Koning APJ, Jones KL, Tomback DF, Oyler-McCance SJ, Fike JA, Lance SL, Streicher JW, Smith EN, and Pollock DD. 2012. Rapid Microsatellite Identification from Illumina Paired-End Genomic Sequencing in Two Birds and a Snake. Plos One 7:e30953. 10.1371/journal.pone.0030953

Cheng T, and Tang R. 1982. A new subspecies of Garrulax galbanus from Yunnan, China - Garrulax galbanus simaoensis. Sinozoologica 2:1-2.

Collar N, Robson C, and Sharpe CJ. 2016. Blue-crowned Laughingthrush (Dryonastes courtoisi). In: del Hoyo J, Elliott A, Sargatal J, Christie DA, and de Juana E, eds. Handbook of the birds of the world alive. Lynx Edicions, Barcelona.

Collar N, Robson C, and Sharpe CJ. 2019. Blue-crowned Laughingthrush (Garrulax courtoisi). In: del Hoyo J, Elliott A, Sargatal J, Christie DA, and de Juana E, eds. Handbook of the Birds of the World Alive. Lynx Edicions, Barcelona.

Collar NJ, and van Balen S. 2013. Notes for the conservation of the Rufous-fronted Laughingthrush Garrulax rufifrons. Forktail 1:15-18.

Davey JW, Hohenlohe PA, Etter PD, Boone JQ, Catchen JM, and Blaxter ML. 2011. Genome-wide genetic marker discovery and genotyping using next-generation sequencing. Nature Reviews Genetics 12:499-510.

Dawson DA, Horsburgh GJ, Kupper C, Stewart IRK, Ball AD, Durrant KL, Hansson B, Bacon I, Bird S, Klein A, Krupa AP, Lee JW, Martin-Galvez D, Simeoni M, Smith G, Spurgin LG, and Burke T. 2010. New methods to identify conserved microsatellite loci and develop primer sets of high cross-species utility - as 
451

452

453

454

455

456

457

458

459

460

461

462

463

464

465

466

467

468

469

470

471

472

473

474

475

476

477

478

479

480

481

482

483

484

485

486

487

488

489

demonstrated for birds. Molecular Ecology Resources 10:475-494. 10.1111/j.1755-0998.2009.02775.x

Earl DA, and Vonholdt BM. 2012. STRUCTURE HARVESTER: a website and program for visualizing STRUCTURE output and implementing the Evanno method. Conservation Genetics Resources 4:359-361. 10.1007/s12686-011-9548-7

Evanno G, Regnaut S, and Goudet J. 2005. Detecting the number of clusters of individuals using the software STRUCTURE: a simulation study. Molecular Ecology 14:2611-2620. 10.1111/j.1365-294X.2005.02553.x

Excoffier L, and Lischer HEL. 2010. Arlequin suite ver 3.5: a new series of programs to perform population genetics analyses under Linux and Windows. Molecular Ecology Resources 10:564-567. 10.1111/j.17550998.2010.02847.x

Faircloth BC. 2008. MSATCOMMANDER: detection of microsatellite repeat arrays and automated, locus-specific primer design. Molecular Ecology Resources 8:92-94. 10.1111/j.1471-8286.2007.01884.x

Falush D, Stephens M, and Pritchard JK. 2003. Inference of population structure using multilocus genotype data: Linked loci and correlated allele frequencies. Genetics 164:1567-1587.

Faria J, Pita A, Rivas M, Martins GM, Hawkins SJ, Ribeiro P, Neto AI, and Presa P. 2016. A multiplex microsatellite tool for conservation genetics of the endemic limpet Patella candei in the Macaronesian archipelagos. Aquatic Conservation-Marine and Freshwater Ecosystems 26:775-781. 10.1002/aqc.2651

Frankham R. 2008. Genetic adaptation to captivity in species conservation programs. Molecular Ecology 17:325-333. 10.1111/j.1365-294X.2007.03399.x

Frankham R. 2010. Challenges and opportunities of genetic approaches to biological conservation. Biological Conservation 143:1919-1927. 10.1016/j.biocon.2010.05.011

Frankham R, Ballou JD, and Briscoe DA. 2010. Introduction to conservation genetics 2 nd edn. Cambridge, UK.: Cambridge University Press.

Gardner L. 2013. International Blue-crowned Laughingthrush Dryonastes courtoisi studbook - No.1 Date current to 31st December 2013. ZSL London Zoo.

Groth JG. 1998. Molecular phylogenetics of finches and sparrows: consequences of character state removal in cytochrome b sequences. Molecular Phylogenetics and Evolution 10:377-390. 10.1006/mpev.1998.0540

Gu LY, Liu Y, Wang N, and Zhang ZW. 2012. A panel of polymorphic microsatellites in the Blue Eared Pheasant (Crossoptilon auritum) developed by cross-species amplification. Chinese Birds 3:103-107. $10.5122 /$ cbirds. 2012.0010

Guo SW, and Thompson EA. 1992. Performing the exact test of Hardy-Weinberg proportion for multiple alleles. Biometrics 48:361-372.

He FQ, Lin JS, Wen C, Lin Z, Shi QH, Huang HQ, Cheng SL, and Xiao H. 2017. Prelim of biology of the Bluecrowned Laughingthrush Garrulax courtoisi in Wuyuan of NE Jiangxi, SE China. Chinese Journal of Zoology 52:167-175.

Kalinowski ST. 2005. Do polymorphic loci require large sample sizes to estimate genetic distances? Heredity 94:3336.

Kalinowski ST, Taper ML, and Marshall TC. 2007. Revising how the computer program CERVUS accommodates genotyping error increases success in paternity assignment. Molecular Ecology 19:1099-1106. http://dx.doi.org/10.1111/j.1365-294x.2007.03089.x 
490 Kalinowski ST, Wagner AP, and Taper ML. 2006. MLrelate: a computer program for maximum likelihood estimation 491 of relatedness and relationship. Molecular Ecology Notes 6:576-579.

492 Konovalov DA, and Heg D. 2008. A maximum-likelihood relatedness estimator allowing for negative relatedness values. Molecular Ecology Resources 8:256-263. 10.1111/j.1471-8286.2007.01940.x

Leigh JW, and Bryant D. 2015. POPART: full-feature software for haplotype network construction. Methods in Ecology and Evolution 6:1110-1116. 10.1111/2041-210x.12410

496

Li C. 2009. Sailing through the Late Pleistocene: unusual historical demography of an East Asian endemic, the Chinese

497

498

499

500

501

502

503

504

505

506

507

508

509

510

511

512

513

514

515

516

517

518

519

520

521

522

523

524

525

526

527

528 Hwamei (Leucodioptron canorum canorum), during the last glacial period (vol 18, pg 622, 2009). Molecular Ecology 18:2921-2921. 10.1111/j.1365-294X.2009.04241.X

Li RQ, Zhu HM, Ruan J, Qian WB, Fang XD, Shi ZB, Li YR, Li ST, Shan G, Kristiansen K, Li SG, Yang HM, Wang J, and Wang J. 2010. De novo assembly of human genomes with massively parallel short read sequencing. Genome Research 20:265-272. 10.1101/gr.097261.109

Librado P, and Rozas J. 2009. DnaSP v5: a software for comprehensive analysis of DNA polymorphism data. Bioinformatics 25:1451-1452. 10.1093/bioinformatics/btp187

Liu DQ, Wan CC, Fu WK, Lin JS, and Wu ZY. 2017. Observation of Blue-crowned Laughingthrush nestling behaviors in Wuyuan, Hong Kong and Nanchang. Chinese Journal of Wildlife 38:249-253.

Liu DQ, Wu ZY, Wang XH, Huang HL, and Li DT. 2016. Cooperative breeding behavior of captive Blue-crowned Laughingthrush (Garrulax courtoisi). Chinese Journal of Wildlife 37:228-233.

Liu Y, Keller I, and Heckel G. 2011. Range-wide genetic population structure of common pochard (Aythya ferina): a potentially important vector of highly pathogenic avian influenza viruses. Ecology and Evolution 1:529-545. $10.1002 /$ ece 3.46

Liu Y, Keller I, and Heckel G. 2013. Temporal genetic structure and relatedness in the Tufted Duck Aythya fuligula suggests limited kin association in winter. Ibis 155:499-507. 10.1111/ibi.12059

Luikart G, England PR, Tallmon D, Jordan S, and Taberlet P. 2003. The power and promise of population genomics: from genotyping to genome typing. Nature Reviews Genetics 4:981-984.

Lynch M, and Walsh B. 1998. Genetics and Analysis of Quantitative Traits. Sinauer Associates, Inc. Sunderland, MA.

Paetkau D, Slade R, Burden M, and Estoup A. 2004. Genetic assignment methods for the direct, real - time estimation of migration rate: a simulation-based exploration of accuracy and power. Molecular Ecology 13:55-65. 10.1046/j.1365-294X.2003.02008.x

Peakall R, and Smouse PE. 2012. GenAlEx 6.5: genetic analysis in Excel. Population genetic software for teaching and research-an update. Bioinformatics 28:2537-2539. 10.1093/bioinformatics/bts460

Pritchard JK, Stephens M, and Donnelly P. 2000. Inference of population structure using multilocus genotype data. Genetics 155:945-959.

Queller DC, and Goodnight KF. 1989. Estimating relatedness using genetic markers. Evolution 43:258-275.

Rice WR. 1989. Analyzing tables of statistical tests. Evolution 43:223-225.

Rosenberg NA. 2004. DISTRUCT: a program for the graphical display of population structure. Molecular Ecology Notes 4:137-138.

Rozen S, and Skaletsky H. 2000. Primer3 on the WWW for general users and for biologist programmers. In: Krawetz S, and Misener S, eds. Bioinformatics methods and protocols: methods in molecular biology. Humana Press, 
529

530

531

532

533

534

535

536

537

538

539

540

541

542

543

544

545

546

547

548

549

550

551

552

553

554

555

556

557

558

559

560

561

562

563

564

565

566

567

Totowa, NJ, 365-386.

Ryman N, and Jorde PE. 2001. Statistical power when testing for genetic differentiation. Molecular Ecology 10:23612373. DOI 10.1046/j.0962-1083.2001.01345.x

Ryman N, and Palm S. 2006. POWSIM: a computer program for assessing statistical power when testing for genetic differentiation. Molecular Ecology Notes 6:600-602. 10.1111/j.1365-294X.2006.01378.x

Tamura K, Stecher G, Peterson D, Filipski A, and Kumar S. 2013. MEGA6: molecular evolutionary genetics analysis version 6.0. Mol Biol Evol 30:2725-2729. 10.1093/molbev/mst197

Thompson JD, Higgins DG, and Gibson TJ. 1994. CLUSTAL W: improving the sensitivity of progressive multiple sequence alignment through sequence weighting, position-specific gap penalties and weight matrix choice. Nucleic Acids Research 22:4673-4680.

Wang B, Xie X, Liu SM, Wang XJ, Pang H, and Liu Y. 2017. Development and characterization of novel microsatellite markers for the Common Pheasant (Phasianus colchicus) using RAD-seq. Avian Research 8. 10.1186/s40657-017-0060-y

WAZA. 2017. Global Species Management Plan. Downloaded from http://www.waza.org/en/site/conservation/conservation-breeding-programmes/bluecrownedlaughingthrush-gsmp on 25/12/2017.

Weir BS, and Cockerham CC. 1984. Estimating F-statistics for the analysis of population structure. Evolution 38:1358-1370.

Wilkinson R, and Gardner L. 2011. No laughing matter. Zooquaria 74:12-13.

Wilkinson R, and He FQ. 2010a. Conservation of Blue-crowned Laughingthrush Garrulax courtoisi in Wuyuan, Jiangxi, and the search for 'lost' populations in Yunnan and Guanxi, China. BirdingASIA 13:100-105.

Wilkinson R, and He FQ. 2010b. Le garrulaxe de Courtois: conservation in situ. CEPA Magazine 1:12-17.

Wilkinson R, and He FQ. 2010c. Yellow-throated Laughingthrush Garrulax galbanus and Blue-crowned Laughingthrush G. courtoisi - new observations and interpretations on their taxonomy. BirdingASIA 14:7382.

Wilkinson R, He FQ, Gardner L, and Wirth R. 2004. A highly threatened bird - Chinese Yellow-throated Laughing thrushes in China and in zoos. International Zoo News 51:456-469.

Willing EM, Dreyer C, and Van Oosterhout C. 2012. Estimates of genetic differentiation measured by $\mathrm{F}_{\mathrm{ST}}$ do not necessarily require large sample sizes when using many SNP markers. PLoS ONE 7:e42649.

Wu YC, Huang JH, Zhang M, Luo ST, Zhang YH, Lei FM, Sheldon FH, and Zou FS. 2012. Genetic divergence and population demography of the Hainan endemic Black-throated Laughingthrush (Ayes: Timaliidae, Garrulax chinensis monachus) and adjacent mainland subspecies. Molecular Phylogenetics and Evolution 65:482-489. 10.1016/j.ympev.2012.07.005

Yang AL, Chen D, Wang PC, Fu YQ, and Zhang ZW. 2017. Characterization of novel microsatellite markers of the Emei Shan Liocichla using restriction site-associated DNA sequencing. Avian Research 8:115-122. 10.1186/s40657-017-0071-8

Zhang WW, Shi JZ, Huang HQ, and Liu T. 2017. The impact of disturbance from photographers on the Blue-crowned Laughingthrush (Garrulax courtoisi). Avian Conservation and Ecology 12:15. 10.5751/Ace-01007-120115

PeerJ reviewing PDF | (2018:07:29419:2:0:NEW 24 Jan 2019) 
568 Figure legends

569

570 Figure 1. Population structure results for Blue-crowned Laughingthrush. (a) Each line represents

571

572

573

574

575

576

577

578

579

580

581

582

583

584

585

586

587

588

589

590

591

592

593

594

595

596

597

598

599

600

601

602

603

604

605 one individual, and the proportion of population assignment of each individual in relative to each of given genetic cluster is represented by the length of each line. Abbreviations indicate different Blue-crowned Laughingthrush populations (OPHK: Ocean Park Hong Kong, NCZ: Nanchang Zoo). (b) Posterior probability means; Ln P(D) ( \pm SD) increased per K. (c) The scenario of two genetic clusters was shown.

Figure 2. (a) Principal coordinates analysis results for 12 novel microsatellite loci of Blue-crowned Laughingthrush individuals genotyped at 12 microsatellite loci. Different colours represent postulated populations. (b) A biplot of the respective log-likelihood values for individuals from two populations. With log-likelihoods converted to positive values, the lowest value indicates the most likely population of origin. The abbreviations represent the different Blue-crowned Laughingthrush populations (OPHK: Ocean Park Hong Kong, NCZ: Nanchang Zoo).

Figure 3. Haplotype network analysis results for the cytb gene dataset (1017 bp) of Blue-crowned Laughingthrush. Black lines on branches indicate the inferred number of mutation steps between haplotypes or ancestral haplotypes. Circle size is proportional to the number of individuals with a particular haplotype. Abbreviations indicate different Blue-crowned Laughingthrush populations (OPHK: Ocean Park Hong Kong, NCZ: Nanchang Zoo).

Figure 4. Pairwise genetic relatedness among Blue-crowned Laughingthrush individuals. Different colours represent the two study populations (OPHK: Ocean Park Hong Kong, NCZ: Nanchang Zoo). Abbreviations indicate different levels of genetic relatedness (U: unrelated, HS: half-siblings, FS: full-siblings, PO: parent-offspring).

\section{SUPPORTING INFORMATION}

Additional supporting information may be found in the online version of this article:

Table S1. Sample voucher numbers and sequence GenBank accession numbers of two captive Blue-crowned Laughingthrush (Garrulax courtoisi) populations used in this article.

Table S2. Genetic relatedness among analysed pairs of Blue-crowned Laughingthrush individuals.

Table S3. Reads of the 12 microsatellite loci in a sample set of two captive Blue-crowned Laughingthrush populations. 
606

607 Figure S1. Analysis of statistical power to detect significant differentiation based on the 12 608 microsatellite markers used in this study. Datasets with eight predefined levels of population 609 differentiation ( $F_{S T}$ values of $\left.0.001,0.0025,0.005,0.01,0.02,0.05,0.075\right)$ were generated using 610 POWSIM. Statistical power was defined as the proportion of times the null hypothesis of equal 611 allele frequencies across populations was rejected using a chi-square test or a Fisher's exact test. 


\section{Figure 1}

Population structure results for Blue-crowned Laughingthrush

Population structure results for Blue-crowned Laughingthrush. (a) Each line represents one individual, and the proportionof population assignment of each individual in relative to each of given genetic cluster is representedby the length of each line. Abbreviations indicate different Blue-crowned Laughingthrush populations (OPHK: Ocean Park Hong Kong, NCZ: Nanchang Zoo). (b) Posterior probability means; Ln P(D) ( \pm SD) increased per K. (c) individual assignment of two genetic clusters was shown.

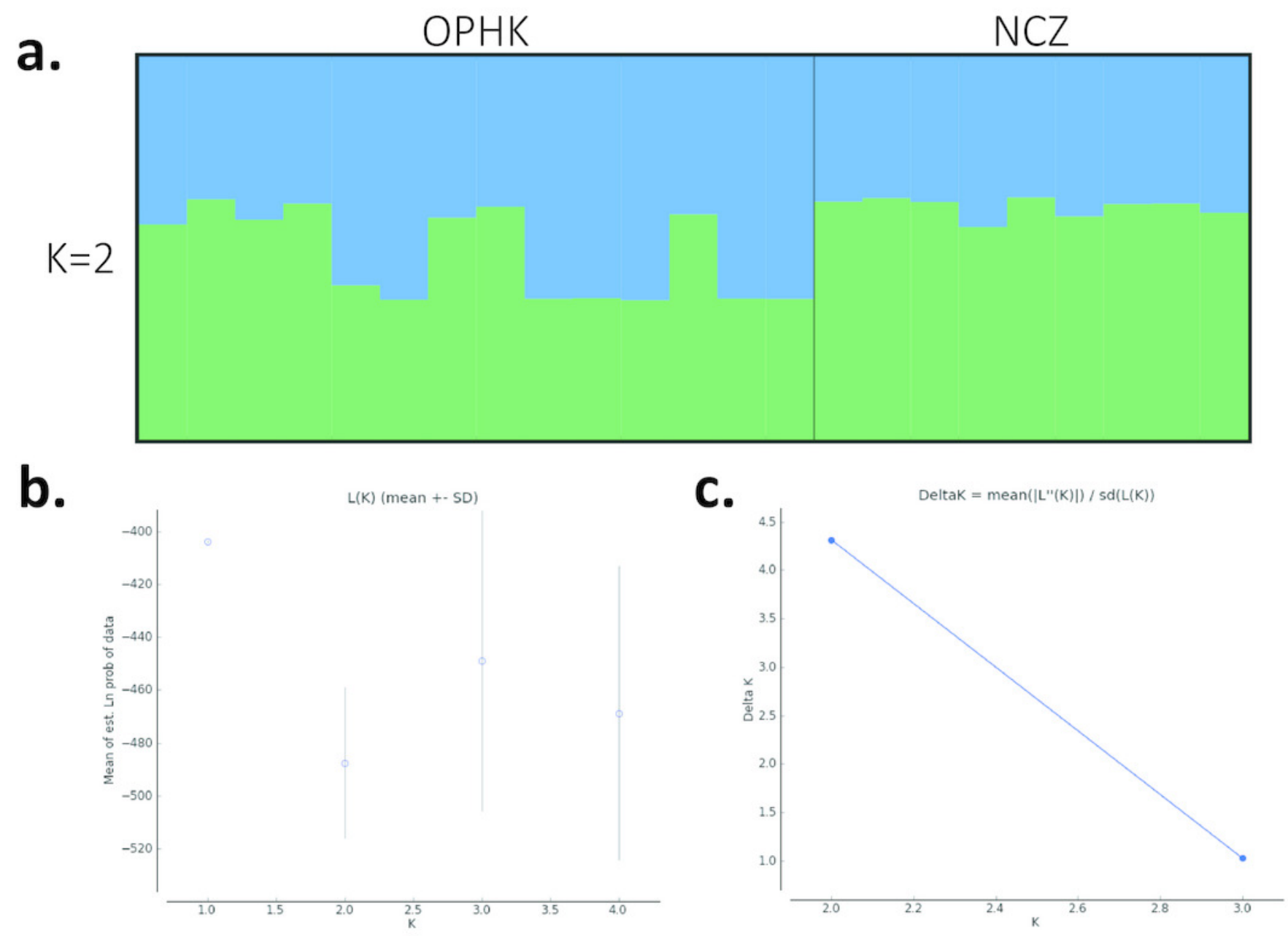




\section{Figure 2}

Principal coordinates analysis and assignment tests

Figure 2. (a) Principal coordinates analysis results for 12 novel microsatellite loci of Bluecrowned Laughingthrush individuals genotyped at 12 microsatellite loci. Different colours represent postulated populations. (b) A biplot of the respective log-likelihood values for individuals from two populations. With log-likelihoods converted to positive values, the lowest value indicates the most likely population of origin. The abbreviations represent the different Blue-crowned Laughingthrush populations (OPHK: Ocean Park Hong Kong, NCZ: Nanchang Zoo). 
a.

Principal Coordinates (PCoA)

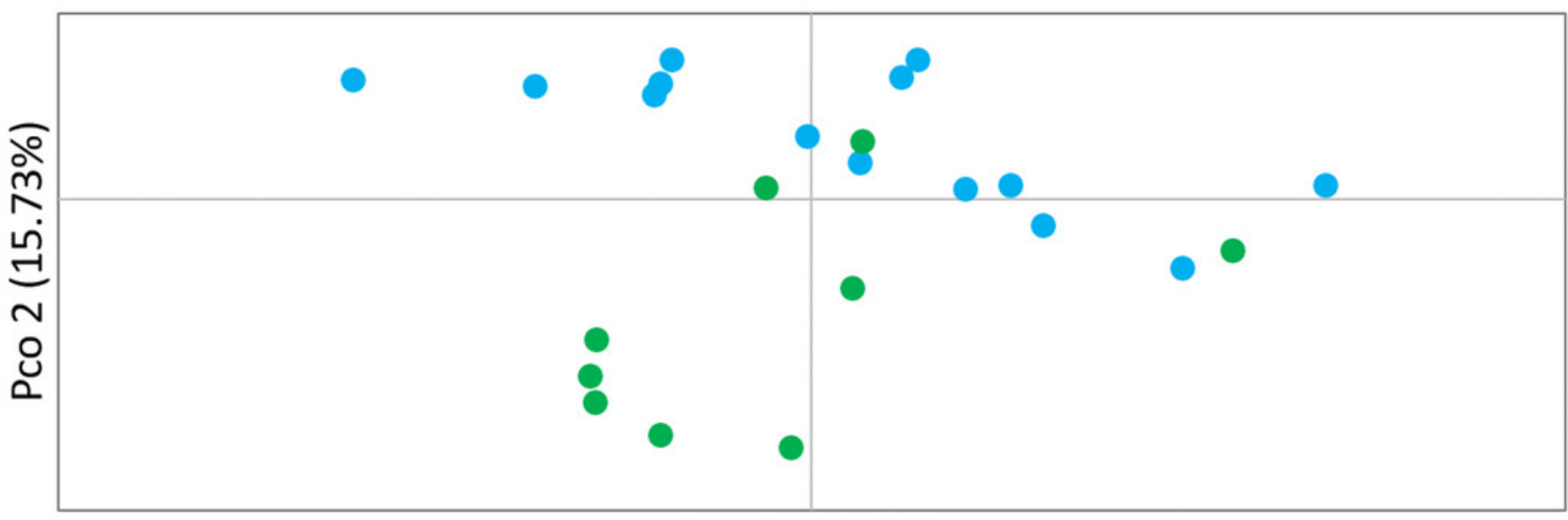

Pco 1 (22.2\%)

- $\mathrm{OPHK} \bullet \mathrm{NCZ}$

b.

Population Assignment

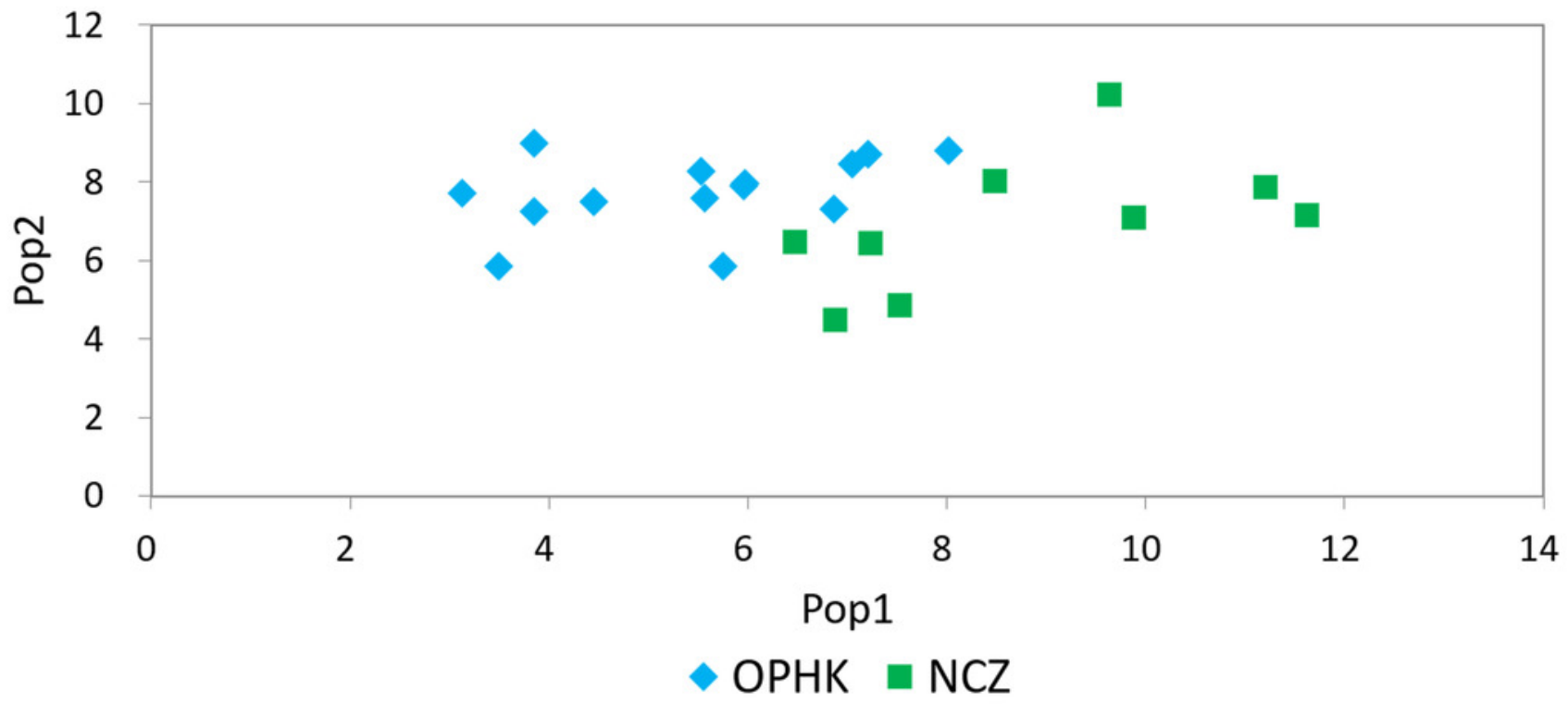




\section{Figure 3}

Haplotype network analysis results for the cytb gene dataset (1017 bp) of Blue-crowned Laughingthrush.

Black lines on branches indicate the inferred number of mutation steps between haplotypes or ancestral haplotypes. Circle size is proportional to the number of individuals with a particular haplotype. Abbreviations indicate different Blue-crowned Laughingthrush populations (OPHK: Ocean Park Hong Kong, NCZ: Nanchang Zoo).

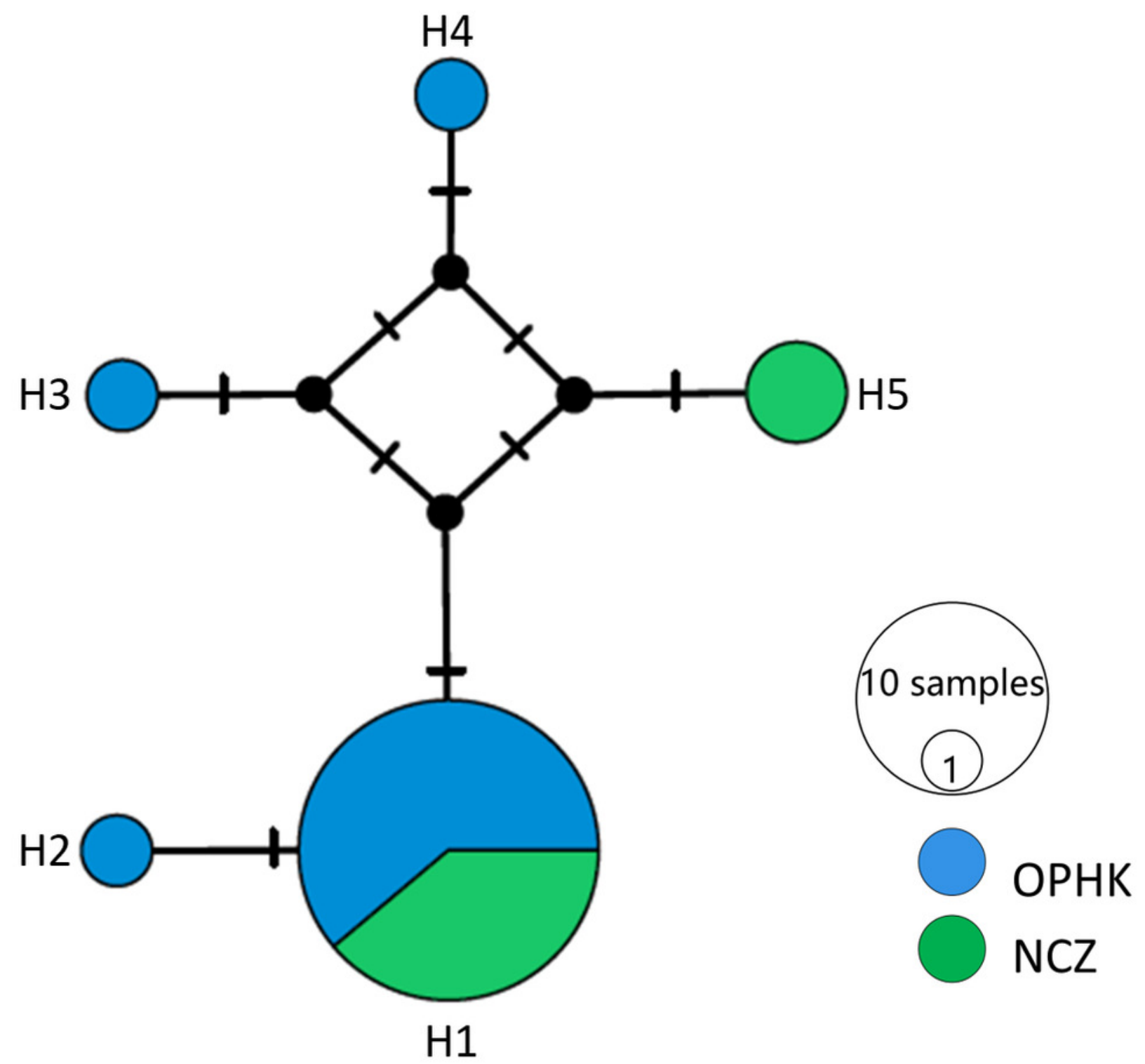




\section{Figure 4}

Pairwise genetic relatedness among Blue-crowned Laughingthrush individuals.

Different colours represent the two study populations (OPHK: Ocean Park Hong Kong, NCZ:

Nanchang Zoo). Abbreviations indicate different levels of genetic relatedness (U: unrelated, HS: half-siblings, FS: full-siblings, PO: parent-offspring).

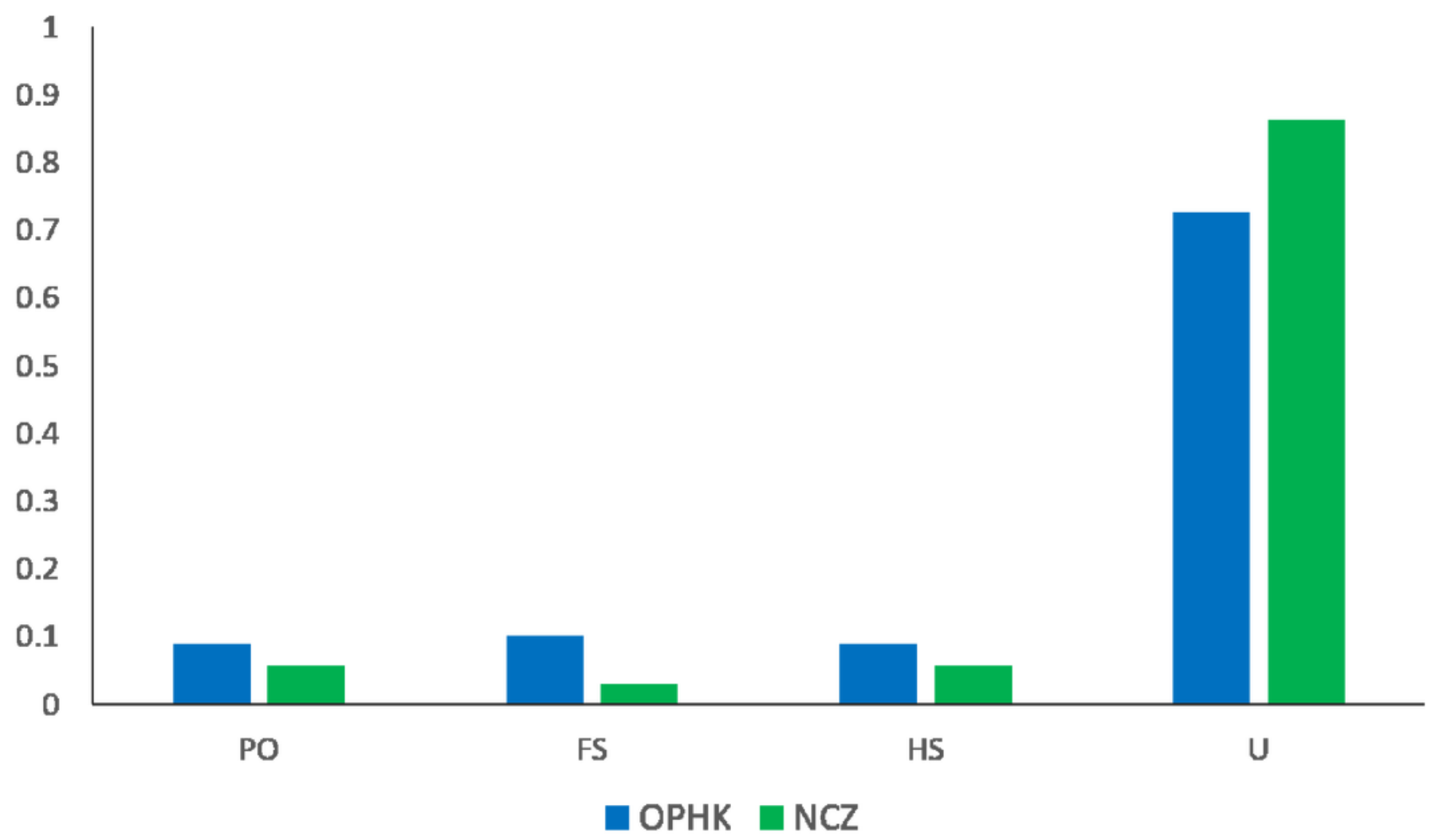




\section{Table $\mathbf{1}$ (on next page)}

Sample voucher numbers and sequence GenBank accession numbers of two captive Blue-crowned Laughingthrush (Garrulax courtoisi) populations used in this article.

(OPHK= Ocean Park, Hong Kong, SYSb=Sun Yat-sen University). 
1 Table 1. Sample voucher numbers and sequence GenBank accession numbers of two captive Blue-

2 crowned Laughingthrush (Garrulax courtoisi) populations used in this article. (OPHK= Ocean Park,

3 Hong Kong, SYSb=Sun Yat-sen University).

4

5

\begin{tabular}{|c|c|c|c|c|}
\hline Taxon & Locality & $\begin{array}{c}\text { Sample } \\
\text { ID/Voucher }\end{array}$ & Gender & $\begin{array}{c}\text { GenBank } \\
\text { accession } \\
\text { number of } \\
\text { cytb } \\
\text { sequence }\end{array}$ \\
\hline \multirow{23}{*}{$\begin{array}{l}\text { Garrulax } \\
\text { courtoisi }\end{array}$} & \multirow{14}{*}{ OPHK, Hong Kong, China } & SYSb6027 & $M$ & MH423582 \\
\hline & & SYSb6028 & $\mathrm{F}$ & $\mathrm{MH} 423583$ \\
\hline & & SYSb6029 & $M$ & MH423584 \\
\hline & & SYSb6030 & $\mathrm{F}$ & MH423585 \\
\hline & & SYSb6031 & $\mathrm{F}$ & MH423586 \\
\hline & & SYSb6032 & $\mathrm{F}$ & MH423587 \\
\hline & & SYSb6033 & $M$ & $\mathrm{MH} 423588$ \\
\hline & & SYSb6034 & M & MH423589 \\
\hline & & SYSb6035 & $M$ & $\mathrm{MH} 423590$ \\
\hline & & SYSb6036 & M & MH423591 \\
\hline & & SYSb6037 & M & MH423592 \\
\hline & & SYSb6038 & $\mathrm{F}$ & MH423593 \\
\hline & & SYSb6039 & $M$ & MH423594 \\
\hline & & SYSb6040 & M & MH423595 \\
\hline & \multirow{9}{*}{ Nanchang Zoo, Jiangxi, China } & SYSb6041 & $M$ & $\mathrm{MH} 423596$ \\
\hline & & SYSb6042 & $\mathrm{F}$ & MH423597 \\
\hline & & SYSb6043 & $\mathrm{F}$ & $\mathrm{MH} 423598$ \\
\hline & & SYSb6044 & M & MH423599 \\
\hline & & SYSb6045 & $\mathrm{F}$ & MH423600 \\
\hline & & SYSb6046 & $M$ & MH423601 \\
\hline & & SYSb6047 & Unknown & $\mathrm{MH} 423602$ \\
\hline & & SYSb6048 & Unknown & $\mathrm{MH} 423603$ \\
\hline & & SYSb6049 & Unknown & $\mathrm{MH} 423604$ \\
\hline
\end{tabular}




\section{Table 2 (on next page)}

Genetic variability in two captive Blue-crowned Laughingthrush (Garrulax courtoisi) populations of the analysed mitochondrial cytochrome $b$ and 12 microsatellite loci.

The number of individuals for which mtDNA $\left(N_{m t}\right)$ and microsatellites $\left(N_{m i}\right)$ were analysed are shown. For mtDNA, the average number of nucleotide differences $(K)$, number of haplotypes $\left(N_{H}\right)$, haplotype diversity $(H \pm S D)$, and nucleotide diversity ( $\pi \pm \mathrm{SD}$, in percent) were calculated. For microsatellites, the average number of different alleles ( $N_{A} \pm \mathrm{SD}$ ), average allelic richness $\left(A_{R} \pm \mathrm{SD}\right)$, mean observed heterozygosity $\left(H_{O} \pm \mathrm{SD}\right)$, and mean expected heterozygosity $\left(H_{E} \pm \mathrm{SD}\right)$ were quantified. The multilocus inbreeding coefficients $\left(F_{I S}\right.$, none of the coefficients were significant) and average pairwise relatedness based on the Queller and Goodnight estimator $\left(R_{Q G} \pm S D\right.$ ) are provided for each population, and values in bold indicate significant deviations from Hardy-Weinberg equilibrium after Bonferroni correction. 
1 Table 2. Genetic variability in two captive Blue-crowned Laughingthrush (Garrulax courtoisi) populations of the analysed

2 mitochondrial cytochrome $b$ and 12 microsatellite loci.

3 The number of individuals for which mtDNA $\left(N_{m t}\right)$ and microsatellites $\left(N_{m i}\right)$ were analysed are shown. For mtDNA, the average number

4 of nucleotide differences $(K)$, number of haplotypes $\left(N_{H}\right)$, haplotype diversity $(H \pm S D)$, and nucleotide diversity ( $\pi \pm$ SD, in percent)

5 were calculated. For microsatellites, the average number of different alleles $\left(N_{A} \pm S D\right)$, average allelic richness $\left(A_{R} \pm\right.$ SD), mean observed

6 heterozygosity $\left(H_{O} \pm S D\right)$, and mean expected heterozygosity $\left(H_{E} \pm S D\right)$ were quantified. The multilocus inbreeding coefficients $\left(F_{I S}\right.$,

7 none of the coefficients were significant) and average pairwise relatedness based on the Queller and Goodnight estimator ( $R_{Q G} \pm$ SD)

8 are provided for each population, and values in bold indicate significant deviations from Hardy-Weinberg equilibrium after Bonferroni

9 correction.

10

\begin{tabular}{|c|c|c|c|c|c|c|c|c|c|c|c|c|}
\hline \multirow[b]{2}{*}{ Population } & \multicolumn{5}{|c|}{ Mitochondrial DNA } & \multicolumn{7}{|c|}{ Microsatellites } \\
\hline & $n$ & $K$ & $N_{H}$ & $H \pm S D$ & $\pi \pm \mathrm{SD}(\%)$ & $n$ & $\mathrm{Na} \pm \mathrm{sd}$ & $A_{R} \pm \mathrm{sd}$ & $H_{O} \pm s \mathrm{~d}$ & $H_{E} \pm s d$ & $F_{l S}$ & $R_{Q G}$ \\
\hline OPHK & 14 & 1.06 & 4 & $0.38 \pm 0.11$ & $0.10 \pm 0.12$ & 14 & $2.50 \pm 0.80$ & $4.42 \pm 3.92$ & $0.36 \pm 0.27$ & $0.34 \pm 0.22$ & -0.214 & $-0.08 \pm 0.52$ \\
\hline NCZ & 9 & 1.10 & 2 & $0.37 \pm 0.11$ & $0.11 \pm 0.17$ & 9 & $2.75 \pm 0.97$ & $5.42 \pm 4.10$ & $0.45 \pm 0.24$ & $0.44 \pm 0.22$ & -0.283 & $-0.13 \pm 0.29$ \\
\hline Total & 23 & 1.11 & 5 & $0.38 \pm 0.09$ & $0.11 \pm 0.13$ & 23 & $3.25 \pm 0.97$ & $6.25 \pm 4.11$ & $0.41 \pm 0.25$ & $0.39 \pm 0.21$ & -0.231 & $-0.05 \pm 0.33$ \\
\hline
\end{tabular}

11 


\section{Table 3 (on next page)}

Characteristics of 12 microsatellite loci in a sample set of two captive Blue-crowned Laughingthrush (Garrulax courtoisi) populations.

The average number of different alleles $\left(N_{A}\right)$, average allelic richness $\left(A_{R}\right)$, mean observed $\left(H_{O} \pm S D\right)$, mean expected $\left(H_{E} \pm S D\right)$, polymorphism information content (PIC), and genetic differentiation index $\left(\mathrm{F}_{\mathrm{ST}}\right.$ * indicates $\left.\mathrm{p}<0.05\right)$ for the OPHK and NCZ populations were estimated for each locus, and values in bold indicate significant deviations from Hardy-Weinberg equilibrium after Bonferroni correction. 
1 Table 3. Characteristics of 12 microsatellite loci in a sample set of two captive Blue-crowned Laughingthrush (Garrulax courtoisi)

2 populations.

3 The average number of different alleles $\left(N_{A}\right)$, average allelic richness $\left(A_{R}\right)$, mean observed $\left(H_{O} \pm \mathrm{SD}\right)$, mean expected $\left(H_{E} \pm \mathrm{SD}\right)$,

4 polymorphism information content $(\mathrm{PIC})$, and genetic differentiation index $\left(\mathrm{F}_{\mathrm{ST}}\right.$, * indicates $\left.\mathrm{p}<0.05\right)$ for the OPHK and NCZ populations

5 were estimated for each locus, and values in bold indicate significant deviations from Hardy-Weinberg equilibrium after Bonferroni

6 correction.

\begin{tabular}{|c|c|c|c|c|c|c|c|c|c|c|}
\hline Locus & $\begin{array}{l}\text { Repeat } \\
\text { motif }\end{array}$ & Primer sequence & $\begin{array}{c}\text { Annealing } \\
\text { temperature }\left({ }^{\circ} \mathrm{C}\right)\end{array}$ & $\begin{array}{c}\text { Size } \\
\text { range(bp) }\end{array}$ & $N_{A}$ & $A_{R}$ & $H_{O}$ & $H_{E}$ & PIC & $\mathrm{F}_{\mathrm{ST}}$ \\
\hline \multirow[t]{2}{*}{ BCLT_L1 } & (TG)6 & F: 5'-CCAAATTCCCCCAGTCCTCC-3' & $58-60$ & 101 & 3 & 3 & 0.261 & 0.241 & 0.222 & -0.008 \\
\hline & & R: 5'-ATGTCAGACACAGCCCGAAC-3' & & & & & & & & \\
\hline \multirow[t]{2}{*}{ BCLT_L2 } & $(A C) 7$ & F: 5'-CCTGCGCATTACCTTGCATC-3' & $58-60$ & 101 & 3 & 4 & 0.087 & 0.086 & 0.082 & -0.019 \\
\hline & & R: 5'-GCAGACACACAGCATTGCAA-3' & & & & & & & & \\
\hline \multirow[t]{2}{*}{ BCLT_L3 } & $(\mathrm{GT}) 7$ & F: 5'-ACAAGTCCCACGTGCTTTCA-3' & $58-60$ & 102 & 3 & 4 & 0.261 & 0.300 & 0.262 & 0.137 \\
\hline & & R: 5'-AAACAGTATCCCCTCCCTGC-3' & & & & & & & & \\
\hline \multirow[t]{2}{*}{ BCLT_L4 } & $(\mathrm{CT}) 6$ & F: 5'-TGACAAACTCTCCCAAGGCC-3' & $58-60$ & 121 & 3 & 4 & 0.391 & 0.341 & 0.308 & 0.075 \\
\hline & & R: 5'-GCTTTAGCAGGGATGTGGGT-3' & & & & & & & & \\
\hline \multirow[t]{2}{*}{ BCLT_L5 } & $(\mathrm{AC}) 7$ & F: 5'-TCCTCAGCTTTCAACCAGGT-3' & $58-60$ & 131 & 4 & 16 & 0.696 & 0.764 & 0.700 & $0.154 *$ \\
\hline & & R: 5'-TCCAGGTGTTGTTCAGTGCA-3' & & & & & & & & \\
\hline \multirow[t]{2}{*}{ BCLT_L6 } & $(\mathrm{TA}) 8$ & F: 5'-AAACCAGCCCTCGACCAAAA-3' & $58-60$ & 188 & 5 & 12 & 0.739 & 0.705 & 0.633 & $0.143^{*}$ \\
\hline & & R: 5'-TCGAGGCTTAATCTGGGTGC-3' & & & & & & & & \\
\hline \multirow[t]{2}{*}{ BCLT_L7 } & $(\mathrm{TA}) 6$ & F: 5'-CCCTTCATTAGCCCTGTGCA-3' & $58-60$ & 216 & 3 & 4 & 0.522 & 0.565 & 0.456 & 0.024 \\
\hline & & R: 5'-TTGTGTGTGTGCATGCCATG-3' & & & & & & & & \\
\hline \multirow[t]{2}{*}{ BCLT_L8 } & $(\mathrm{GT}) 6$ & F: 5'-AGCAGACCAGAGAGCAACAC-3' & $58-60$ & 238 & 2 & 2 & 0.304 & 0.264 & 0.225 & 0.005 \\
\hline & & R: 5'-TGGCAAAGAAGTTGGGGGTT-3' & & & & & & & & \\
\hline BCLT_L9 & (TA)6 & F: 5'-TGGAAGCATACACCACACAGA-3' & $58-60$ & 258 & 5 & 5 & 0.565 & 0.538 & 0.484 & 0.028 \\
\hline
\end{tabular}


R: 5'-GCATTTTCTTCTTGGCTCTCAGT-3'

\begin{tabular}{|c|c|c|c|c|c|c|c|c|c|c|}
\hline \multirow[t]{2}{*}{ BCLT_L10 } & (TAT)5 & F: 5'-GACAGACACGTGCTTCTCCA-3' & $58-60$ & 137 & 3 & 6 & 0.478 & 0.530 & 0.405 & -0.024 \\
\hline & & R: 5'-GCAGGTCACCTCCTGAACTC-3' & & & & & & & & \\
\hline \multirow[t]{2}{*}{ BCLT_L11 } & (GCA)6 & F: 5'-GGTTCACAGCCTCTGGTCTC-3' & $58-60$ & 184 & 2 & 6 & 0.261 & 0.232 & 0.201 & -0.032 \\
\hline & & R: 5'-AGTTCTGGTTGGGAGTGCTG-3' & & & & & & & & \\
\hline \multirow[t]{2}{*}{ BCLT_L12 } & (TAG)5 & F: 5'-TCCACTTCAGTCCCAGGTCA-3' & $58-60$ & 254 & 3 & 9 & 0.174 & 0.165 & 0.154 & 0.007 \\
\hline & & R: 5'-ATGGCAGTTGGGTTGGAACT-3' & & & & & & & & \\
\hline
\end{tabular}

7 